\title{
Self-expandable metallic stent application for the management of upper gastrointestinal tract disease
}

\author{
Arif Emre ${ }^{1}$, Mehmet Sertkaya ${ }^{1}$, Sami Akbulut ${ }^{2}$, Ozan Erbil ${ }^{3}$, Nursel Yurttutan ${ }^{4}$, Illhami Taner Kale ${ }^{1}$ Ertan Bülbüloğlu ${ }^{1}$
}

\section{ABSTRACT}

\section{Cite this paper as:}

Emre A, Sertkaya M, Akbulut

S, Erbil 0, Yurttutan N, Kale

iT, et al. Self-expandable

metallic stents for upper

gastrointestinal tract disease:

Clinical experiences. Turk J

Surg 2018; 34: 101-105.

This study was presented at the

"33. National Gastroenterology

Week, "22-27 November 2016",

"Antalya, Turkey".

'Department of General Surgery,

Sütçü İmam University School of

Medicine, Kahramanmaraş, Turkey

2Department of General Surgery,

Inönü University School of

Medicine, Malatya, Turkey

${ }^{3}$ Department of General Surgery,

Gebze State Hospital, İzmit, Turkey

${ }^{4}$ Department of Radiology,

Sütçü Imam University School of

Medicine, Kahramanmaraş, Turkey

\section{Corresponding Author}

\section{Sami Akbulut}

e-mail: akbulutsami@gmail.com

Received: 19.10 .2016

Accepted: 18.05.2017

Available Online Date: 30.04 .2018

(c) Copyright 2018

by Turkish Surgical Association

Available online at

www.turkjsurg.com
Objective: The aim of the present study was to share our experiences of the use of self-expandable metallic stent for the upper gastrointestinal tract disease.

Material and Methods: We retrospectively reviewed the medical records of 18 patients who underwent self-expandable metallic stent implantation procedure for anastomosis stricture, anastomosis leak, or spontaneous fistula of the upper gastrointestinal tract at two different surgery clinics. Self-expandable metallic stent implantation procedures were performed while keeping the patient under sedation and the correct stent localization was verified using fluoroscopy. The stent localization and possible stent migration were checked using X-ray films taken a few days after the stenting procedure.

Results: Overall, 25 self-expandable metallic stents were implanted in 18 patients (malignant, 13; benign, 5) aged between 19 and 89 years. The indications for self-expandable metallic stent implantation were as follows: malignant gastric stricture (inoperable; $n=6$ ), malignant esophageal stricture (inoperable; $n=4$ ), staple line leak (laparoscopic sleeve gastrectomy; $n=4$ ), esophagojejunostomy anastomotic leak (total gastrectomy+Roux-en-Yesophagojejunostomy; $n=2$ ), and stricture (total gastrectomy+Roux-en-Yesophagojejunostomy; $n=1$ ), and esophagopleural fistula (pulmonary tuberculosis; $n=1$ ). A favorable outcome was achieved in a single session in 15 patients, whereas more than two sessions of stenting were necessary in the remaining three patients. Among the patients who underwent esophagojejunal anastomosis $(n=3)$, self-expandable metallic stents were successfully deployed in a single session in two patients to relieve anastomosis leak $(n=1)$ and anastomosis stricture $(n=1)$; the remaining patients underwent four self-expandable metallic stent implantation procedures to relieve anastomosis leak and subsequent recurrent strictures. No complications developed during the stenting procedure. Three of the four patients who developed mortality had advanced stage esophageal cancer, whereas one patient had morbid obesity and developed staple line leakage.

Conclusion: Endoscopic self-expandable metallic stent implantation under fluoroscopic guidance is a low-morbidity and effective procedure for the management of advanced stage tumors of the gastrointestinal tract and the elimination of postoperative complications.

Keywords: Leakage, metallic stents, stenosis, upper gastrointestinal tract

\section{INTRODUCTION}

Until the last quarter century, many treatment modalities, particularly the surgical ones (open/laparoscopic), have been used for the primary management of some benign and malignant conditions of the upper gastrointestinal tract and their complications (1-4). Owing to recent technological advances in endoscopic devices and the introduction of novel stent materials, the endoscopic approach has become the first option $(1,4-7)$. This approach has been widely used owing to its minimally invasive nature and feasibility under mild sedation (8-16). The aim of the present study was to share with the readers our experience of using self-expandable metallic stents (SEMSs) for the treatment of complications involving the upper gastrointestinal tract, such as fistula and stricture.

\section{MATERIAL AND METHODS}

We retrospectively reviewed the demographic, clinical, endoscopic, and radiological records of 18 consecutive patients who underwent SEMS implantation (Hanarostent, M.I. Tech Co. Ltd., Pyeongtaek, South Korea) for malignant disorders and benign complications (anastomosis stricture, anastomosis leak, and spontaneous fistula) affecting the upper gastrointestinal tract at the Department of Surgery, Sutcu Imam University Faculty of Medicine, Kahramanmaras and Department of Surgery, Gebze Fatih State Hospital, Izmit, Turkey. All SEMS implantation procedures were performed by two independent surgeons (AE and OE) experienced in endoscopy, fluoroscopy, and endoscopic stenting. Depending on the area and region of complication, stents with various characteristics were used. The technical characteristics of the stents used in this study are as follows: a $210-\mathrm{mm}$ long Hanarostent ${ }^{\oplus}$ Esophagus Bariatric Surgery (ECBB-28-210-090) stent was used for 4 cases with leaks at stapler line after bariatric surgery. A 100-mm long Hanarostent ${ }^{\oplus}$ Esophagus Benign BS (CCC) (EBN22080-Z070) stent was used for complications with esophagojejunostomy anastomosis 
Table 1. Demographic and clinical characteristics of 18 patients treated with self-expandable metallic stents

\begin{tabular}{|c|c|c|c|c|c|}
\hline No. & Age & Gender & Underlying cause & Performed surgery & Stent indication \\
\hline 1 & 37 & Male & Gastric cancer & $\begin{array}{l}\text { Total Gastrectomy + Roux-en-Y } \\
\text { Esophagojejunostomy }\end{array}$ & Esophagojejunostomy anastomotic leak \\
\hline 2 & 61 & Male & Esophageal cancer (S:IV) & No & Malignant esophageal stricture \\
\hline 3 & 71 & Male & Gastric cancer & $\begin{array}{l}\text { Total Gastrectomy + Roux-en-Y } \\
\text { Esophagojejunostomy }\end{array}$ & Esophagojejunostomy anastomotic leak \\
\hline 4 & 33 & Female & Gastric cancer & $\begin{array}{l}\text { Total Gastrectomy + Roux-en-Y } \\
\text { Esophagojejunostomy }\end{array}$ & Esophagojejunostomy anastomotic stricture \\
\hline 5 & 36 & Female & Pulmonary tuberculosis & No & Esophagopleural fistula \\
\hline 6 & 53 & Male & Esophageal cancer (S:IV) & No & Malignant esophageal stricture \\
\hline 7 & 19 & Female & Morbid obesity & Laparoscopic sleeve gastrectomy & Staple line leak \\
\hline 8 & 34 & Female & Morbid obesity & Laparoscopic sleeve gastrectomy & Staple line leak \\
\hline 9 & 46 & Male & Morbid obesity & Laparoscopic sleeve gastrectomy & Staple line leak \\
\hline 10 & 21 & Male & Morbid obesity & Laparoscopic sleeve gastrectomy & Staple line leak \\
\hline 11 & 67 & Male & Gastric Cancer (Antrum) & No & Malignant gastric stricture \\
\hline 12 & 80 & Female & Gastric Cancer (Antrum) (S:IV) & No & Malignant gastric stricture \\
\hline 13 & 71 & Female & Gastric Cancer (Antrum) (S:IV) & No & Malignant gastric stricture \\
\hline 14 & 62 & Female & Gastric Cancer (Antrum) (S:IV) & No & Malignant gastric stricture \\
\hline 15 & 51 & Male & Gastric Cancer (Antrum) (S:IV) & No & Malignant gastric stricture \\
\hline 16 & 74 & Female & Esophageal cancer (S:IV) & No & Malignant esophageal stricture \\
\hline 17 & 89 & Female & Esophageal cancer (S:IV) & No & Malignant esophageal stricture \\
\hline 18 & 59 & Female & Gastric Cancer (Antrum) & No & Malignant gastric stricture \\
\hline
\end{tabular}

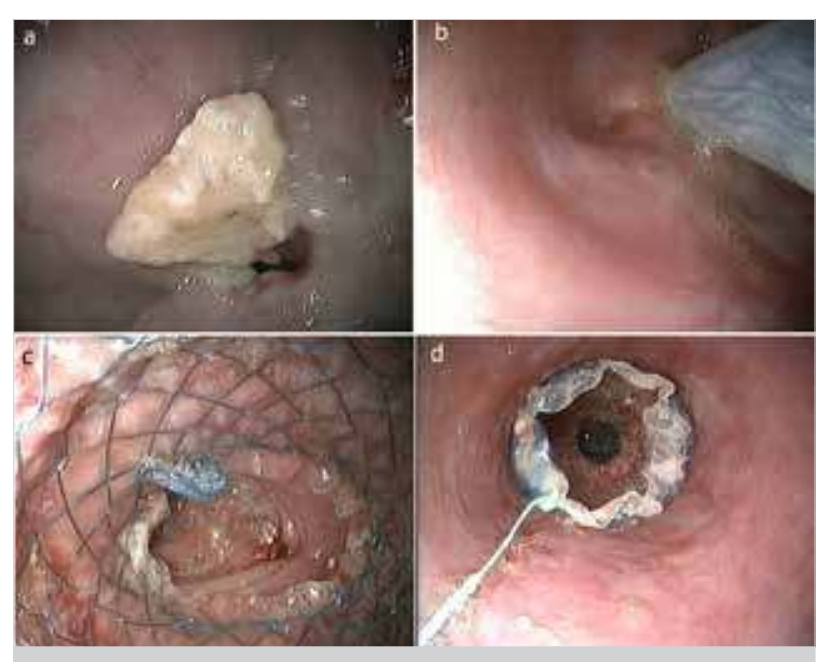

Figure 1. a-d. Some images of the stent implantation stage in patient with esophagial stricture secondary to cancer

after gastric cancer surgery. A 70-mm long and a 140-mm long Hanarostent ${ }^{\oplus}$ Esophagus Skid proof (ECD-20-180-070 and ECD20-120-070) stents were used for 4 cases with malignant esophageal stricture. A $100-\mathrm{mm}$ long Hanarostent ${ }^{\oplus}$ Esophagus Benign BS (CCC) (EBN22080-Z070) was implanted in a case with benign esophagopleural fistula. All patients who were scheduled for SEMS implantation procedures were fasted overnight before the procedure. Antibiotics were administered to all participants prior to the procedure. The stenting procedure was performed at the stent under endoscopic guidance, fluoroscopy was used to verify correct stent localization. Implantation of a stent to a correct position was defined as technical success. Complete elimination of the complication (stricture, fistula and leak) after stenting was defined as clinical success. Persistence of complications or death secondary to the persistence of complications despite stenting was defined as clinical failure.

X-ray imaging and endoscopy were performed one or a couple of days after the stenting procedure to check correct stent position and/or if migration occurred. Patients with appropriate stent localization were fed orally after 2-3 days of the procedure. In patients presenting with any gastrointestinal discomfort after discharge, one or a combination of examination findings, laboratory tests, radiological studies (plain radiographs and (T), and endoscopic examination were performed to check whether any stent-related complication developed. Eight out of 10 patients received temporary stents, whereas 2 received permanent stents. Time of stent removal was determined based on the time of elimination of complications and patient satisfaction. Quantitative variables were stated as mean \pm standard deviation and range (minimum-maximum), and qualitative variables were given as number with percent.

This study was conducted according to the Declaration of Helsinki and local approval was obtained from Kahramanmaraş Sütçü İmam School of Medicine Ethics Committee. Informed consent was obtained from all patients. 


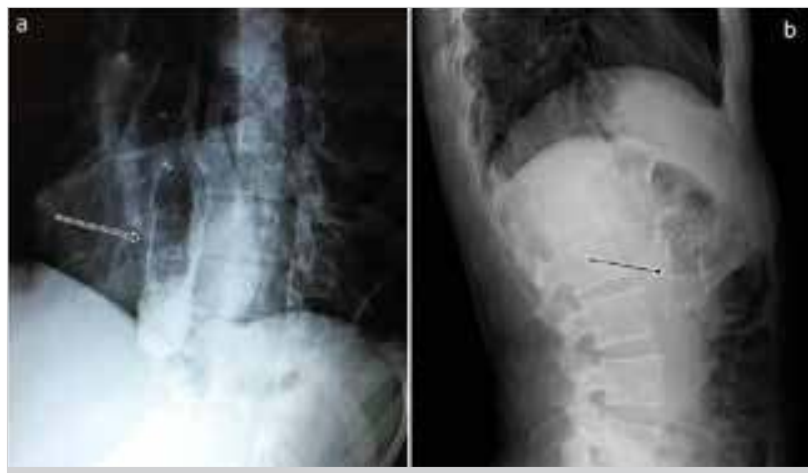

Figure 2. a, b. Radiologic appearance of stent migration to $3^{\text {rd }}$ part of duodenum
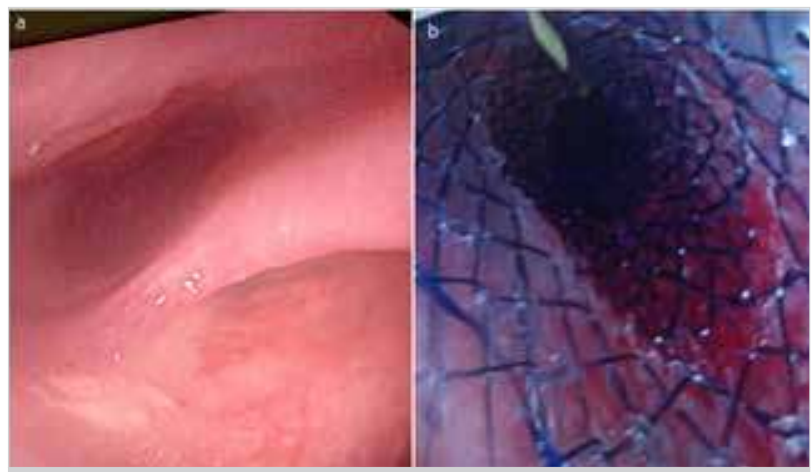

Figure 3. a, b. Management of patient with esophagopleural fistula

Table 2. Properties of the applied stents and outcomes of the 18 patients treated with self-expandable metallic stents

\begin{tabular}{|c|c|c|c|c|c|c|c|}
\hline No & Type of stent & $\begin{array}{l}\text { Length of } \\
\text { Stent }(\mathrm{mm})\end{array}$ & $\begin{array}{l}\text { Interval Between } \\
\text { Stenting and Operat }\end{array}$ & Migration & Restenting & $\begin{array}{l}\text { Additional } \\
\text { Application }\end{array}$ & Outcome \\
\hline 1 & Covered Metalic & 100 & 3 & Yes & Yes* & $\begin{array}{l}\text { Dilatation }+ \\
\text { Submucosal steroid }\end{array}$ & Alive \\
\hline 2 & Covered Metalic & 140 & No-operated & No & No & No & Exitus \\
\hline 3 & Covered Metalic & 100 & 13 & No & No & No & Alive \\
\hline 4 & Covered Metalic & 100 & 90 & No & No & No & Alive \\
\hline 5 & Covered Metalic & 100 & No-operated & No & No & No & Alive \\
\hline 6 & Covered Metalic & 80 & No-operated & No & No & No & Alive \\
\hline 7 & Covered Metalic & 210 & 19 & No & No & No & Exitus \\
\hline 8 & Covered Metalic & 210 & 13 & No & No & No & Alive \\
\hline 9 & Covered Metalic & 210 & 10 & No & No & No & Alive \\
\hline 10 & Covered Metalic & 210 & 17 & No & No & No & Alive \\
\hline 11 & Non-Covered Methalic & 120 & No-operated & No & No & No & Alive \\
\hline 12 & Non-Covered Methalic & 160 & No-operated & No & No & No & Alive \\
\hline 13 & Non-Covered Methalic & 160 & No-operated & No & No & No & Alive \\
\hline 14 & Non-Covered Methalic & 160 & No-operated & No & No & No & Alive \\
\hline 15 & Non-Covered Methalic & 160 & No-operated & No & No & No & Alive \\
\hline 16 & Non-Covered Methalic & 90 & No-operated & Yes & Yes ** & No & Exitus \\
\hline 17 & Non-Covered Methalic & 70 & No-operated & Yes & Yes ** & No & Exitus \\
\hline 18 & Non-Covered Methalic & 160 & No-operated & No & No & No & Alive \\
\hline
\end{tabular}

\section{RESULTS}

The medical records of a total of 18 patients aged between 19 and 89 years (mean \pm SD: $53.5 \pm 20.3$ years), of whom 8 (44.40\%) were males and 10 (55.6\%) were females, were retrospectively reviewed. The age ranged from 21 to 71 years (mean \pm SD: $50.8 \pm 16.4$ years) for male patients and 19 to 89 years (mean $\pm S D$ : $55.7 \pm 23.7$ years) for female patients. There was a significant difference between the mean ages of both sexes $(p<0.001)$.

A favorable outcome was achieved in 15 (83.3\%) of 18 patients undergoing a single session of SEMS implantation procedures, whereas 3 patients needed more than two sessions of SEMS implantation procedures. Temporary SEMS implantation was performed to eliminate complications in $8(44.4 \%)$ patients, whereas permanent SEMS implantation was performed in 10 (55.6\%) patients with advanced esophageal or gastric cancer.

In more than $70 \%$ of patients undergoing SEMS implantation, the primary underlying pathologies were esophageal cancer $(n=4)$ and gastric cancer $(n=9)$. Malignant esophageal strictures restricting food intake and causing severe chest pain were detected in both patients with advanced esophageal cancer (Figure 1). Permanent SEMSs were implanted in all patients. Three of the patients were lost to metastatic cancer despite total clinical and technical success. Among the three patients who underwent total gastrectomy with Roux-en-Y esophagojejunostomy because of gastric cancer, two developed anastomosis leak and one anastomosis stricture after the operation. All three patients underwent SEMS implantation. In 
two of the patients, anastomosis leak and stricture were completely eliminated after stenting, and stents were retrieved endoscopically in a short time. Despite this, a total of four stenting sessions were needed in a 37-year-old patient. Despite the elimination of esophagojejunostomy anastomosis leak after the first stenting procedure in that patient, a resistant anastomotic stricture developed approximately 2 months later. To solve the stricture issue, a total of four sessions of bougie dilatation and submucosal steroid injection were performed at a 15-day interval. Persistence of symptoms despite these measures necessitated a second stenting procedure in that patient, who developed severe resistant chest pain leading to endoscopic stent retrieval 15 days after the second stenting procedure. A third stent was implanted because of recurrent stricture-related complaints during follow-up. However, the stent migrated distally 2 days after the procedure (Figure 2 ). The migrated stent was spontaneously eliminated without a need for any additional intervention. The patient underwent a fourth stenting procedure 1 month later because of persisting stricture-related complaints. No stricture was detected at a 6-month follow-up.

In more than $27 \%$ of patients, SEMSs were implanted in the stomach $(n=4)$ and esophagus $(n=1)$ for benign conditions. Of these patients, four underwent the procedure for stapler line leak after laparoscopic sleeve gastrectomy for morbid obesity, whereas the other patient received a stent for esophagopleural fistula secondary to pulmonary tuberculosis. A 19-year-old woman with mental retardation and multiple comorbidities, who underwent sleeve gastrectomy, developed an abscess in the vicinity of the stomach following anastomosis leak. The complication was first intervened with percutaneous drainage but her metabolic condition and infectious parameters did not recover; therefore, an SEMS was implanted. The patient was lost to multiple organ failure 2 days after the stenting procedure. A 36-year-old woman without previously known pulmonary tuberculosis had been diagnosed with esophagopleural fistula at another center. At the same institution, lung tuberculosis had been also diagnosed, and anti-tuberculous treatment had been started. The patient received an esophageal stent in a single session. Her stent was retrieved endoscopically 40 days later when cessation of leak was radiologically confirmed (Figure 3). Tables 1 and 2 show the demographic, clinical, and follow-up data of all patients included in the present study.

\section{DISCUSSION}

Endoscopic stents have been widely used for the treatment of many benign and malignant conditions of the gastrointestinal tract, which formerly could be treated solely by surgical therapy. Stents have also been used to replace invasive procedures, such as relaparotomy, in the management of many postoperative complications $(12,13,15)$. Widespread use of stents in many centers worldwide and their favorable outcomes have led to the use of these devices by many surgeons in a courageous manner. This paved the way for progressively increasing diversity of stenting indications and stent quality. It is now possible to access many stents of variable properties and types in many countries worldwide. No significant differences exist between the technical and clinical success rates of covered and uncovered stent applications, both of which are currently widely used (12). Uncovered stents prevent obstruc- tive jaundice when used for the palliation of pathologies with special location (such as those located where the common bile duct opens into the duodenum) that cause strictures in the gastrointestinal system (13). Covered stents have the disadvantage of having a greater tendency to migrate, whereas uncovered stents have a greater tendency of being obstructed. In the present, in addition to the management of benign esophageal strictures, leaks, and perforations, stents are used for the palliative treatment of malignant dysphagia and gastric outlet obstruction, esophageal leaks following surgery, and/ or stapler line leaks following sleeve gastrectomy. The success rate ranges between $72 \%$ and $100 \%(12,16,17)$. Among the cases presented in the present study, 7 received covered stents because of leak $(n=6)$ or fistula $(n=1)$, although the success of stenting could not be determined because one patient died on the second day of stenting.

Self-expandable metallic stent ensures a much lower mortality and morbidity than surgical procedures, in the form of either primary operations or relaparotomy procedures. In conclusion, SEMS implantation is a highly effective treatment for eliminating a variety of complications following surgery, starting oral feeding at an early period, shortening the duration of hospital stay, eliminating/palliating symptoms such as pain, preventing aspiration-associated infections, reducing overall cost, preventing recurrent laparotomies, and improving the quality of life (17-19). Although we had experience in biliary stent implantation for a long time, we performed first stent implantation in the gastrointestinal tract 18 months ago. We employed the stenting procedure for palliative treatment of dysphagia in two of our patients and for definitive treatment in the remaining patients.

Literature reports have stated mild, moderate, or severe chest pain as the most common complicationsof stent implantation in the upper gastrointestinal tract $(12 \%-30 \%)(12,13,15,20)$. Pain results from an increased pain sensitivity in the upper part of the esophagus and from mucosal erosion caused by reflux as a result of surgeries in the lower part. Fortunately, pain usually subsides after the administration of medication, such as analgesics and antireflux drugs. The other complications after stenting include bleeding, restenosis ( $0 \%-6 \%)$, stent folding, early or late migration $(0 \%-58 \%)$, pneumomediastinum, tracheoesophageal fistula $(0 \%-10 \%)$, perforation $(0 \%-4.9 \%)$, and stent obstruction by food materials $(8,9,17,20)$. These complications are usually eliminated by medications or circumstance-specific treatments, although surgical therapy is also seldom required.One of our patients with gastric cancer developed anastomosis leak, resistant stricture, chest pain, and stent migration. Occurrence of these four complications in a single patient at different time points was considered bad luck. The patient received a total of four stents at four different times.

Four of 18 patients presented here died. Three patients who presented with advanced esophageal cancer underwent stenting for palliative purposes. However, two patients were extremely cachectic and were lost to metabolic complications of the tumor, although the patient's tolerance to oral food was well. Hence, mortality of these patients was not directly related to stenting. The other patient was lost 2 days after stenting because of leak after sleeve gastrectomy. A medical approach followed by interventional radiological approaches was selected 
for treating the patient's leak. The patient was consulted and stented by us after the emergence of multiple organ failure. However, the patient was lost despite stenting because the clinical condition became irreversible. We also consider the loss of the patient independent of the stenting procedure and believe that an early stenting attempt could have brought the leak under control. In summary, our experience obtained from both deceased patients and the remaining successful cases is that an early stenting procedure is significant in cases with accurate indications.

\section{CONCLUSION}

Endoscopic stenting procedure is characterized by high patient comfort and low morbidity and mortality rates and is employed for primary treatment and postoperative complication management of many benign and malignant disorders of the upper gastrointestinal tract.

Ethics Committee Approval: Ethics committee approval was received for this study from the ethics committee of Kahramanmaraş Sütçü Imam University School of Medicine.

Informed Consent: Written informed consent was obtained from patient who participated in this study.

Peer-review: Externally peer-reviewed.

Author Contributions: Concept - A.E., M.S., S.A.; Design - A.E., O.E., N.Y.; Supervision - I.T.K., E.B., A.E.; Resource - A.E.; Materials - A.E., O.E., N.Y.; Data Collection and/or Processing - A.E., O.E., N.Y.; Analysis and/ or Interpretation - A.E., S.A.; Literature Search - A.E., S.A., N.Y.; Writing Manuscript -A.E.; Critical Reviews - I.T.K., A.E., S.A.

Conflict of Interest: The authors have no conflicts of interest to declare.

Financial Disclosure: The authors declared that this study has received no financial support.

\section{REFERENCES}

1. Miłek T, Ciostek P, Petryka R, Słowik J, Jarosz M. Results of endoscopic and surgical fistula treatment in oesophagointestinal anastomosis after gastrectomy. Wideochirlnne Tech Maloinwazyjne 2016; 10: 515-520.

2. Kim JH, Shin JH, Song HY. Fluoroscopically guided balloon dilation for benign anastomotic stricture in the upper gastrointestinal tract. Korean J Radiol 2008; 9: 364-370. [CrossRef]

3. Cheng YS, Li MH, Chen WX, Chen NW, Zhuang QX, Shang KZ. Comparison of different intervention procedures in benign stricture of gastrointestinal tract. World J Gastroenterol 2004; 10: 410414. [CrossRef]

4. Hwang JJ, Jeong YS, Park YS, Yoon H, Shin CM, Kim N, et al. Comparison of Endoscopic Vacuum Therapy and Endoscopic Stent Implantation With Self-Expandable Metal Stent in Treating Postsurgical Gastroesophageal Leakage. Medicine (Baltimore) 2016; 95: 3416. [CrossRef]

5. Farnik H, Driller M, Kratt T, Schmidt C, Fähndrich M, Filmann N, et al Indication for 'Over the scope' (OTS)-clip vs. covered self-ex- panding metal stent (CSEMS) is unequal in upper gastrointestinal leakage: results from a retrospective head-to-head comparison. PLoS One 2015; 10: e0117483. [CrossRef]

6. Raimondo D, Sinagra E, Facella T, Rossi F, Messina M, Spada M, et al. Self-expandable metal stent placement for closure of a leak after total gastrectomy for gastric cancer: report on three cases and review of the literature. Case Rep Gastrointest Med 2014; 2014: 409283. [CrossRef]

7. Parthipun A, Diamantopoulos A, Shaw A, Dourado R, Sabharwal T. Self-expanding metal stents in palliative malignant oesophageal dysplasia. Ann Palliat Med 2014; 3: 92-103.

8. Kang HW, Kim SG. Upper Gastrointestinal Stent Insertion in Malignant and Benign Disorders. ClinEndosc 2015; 48: 187-189. [CrossRef]

9. Kim SG, Yang CH. Upper gastrointestinal stent. ClinEndosc 2012; 45: 386-391. [CrossRef]

10. Morikawa S, Suzuki A, Nakase K, Yasuda K. Palliation of malignant upper gastrointestinal obstruction with self-expandable metal stent. Korean J Radiol 2012; 13: S98-103. [CrossRef]

11. Griffiths EA, Gregory CJ, Pursnani KG, Ward JB, Stockwell RC. The use of biodegradable (SX-ELLA) oesophageal stents to treat dysphagia due to benign and malignant oesophageal disease. SurgEndosc 2012; 26: 2367-2375. [CrossRef]

12. van Halsema EE, van Hooft JE. Clinical outcomes of self-expandable stent placement for benign esophageal diseases: A pooled analysis of the literature. World J Gastrointest Endosc 2015; 7: 135-153. [CrossRef]

13. Pan YM, Pan J, Guo LK, Qiu M, Zhang JJ. Covered versus uncovered self-expandable metallic stents for palliation of malignant gastric outlet obstruction: a systematic review and meta-analysis. BMC Gastroenterol 2014; 14: 170. [CrossRef]

14. Sharma P, Kozarek R. Practice Parameters Committee of American College of Gastroenterology. Role of esophageal stents in benign and malignant diseases. Am J Gastroenterol 2010; 105: 258-273. [CrossRef]

15. Jee SR, Cho JY, Kim KH, Kim SG, Cho JH. Stent Study Group of the Korean Society of Gastrointestinal Endoscopy. Evidence-based recommendations on upper gastrointestinal tract stenting: a report from the stent study group of the korean society of gastrointestinal endoscopy. Clin Endosc 2013; 46: 342-354. [CrossRef]

16. van Boeckel PG, Dua KS, Weusten BL, Schmits RJ, Surapaneni $\mathrm{N}$, Timmer R, et al. Fully covered self-expandable metal stents (SEMS), partially covered SEMS and self-expandable plastic stents for the treatment of benign esophageal ruptures and anastomotic leaks. BMC Gastroenterol 2012; 12: 19. [CrossRef]

17. Dobrucali A, Caglar E. Palliation of malignant esophageal obstruction and fistulas with self expandable metallic stents. World J Gastroenterol 2010; 16: 5739-5745. [CrossRef]

18. Mosca F, Stracqualursi A, Portale TR, Consoli A, Latteri S. Palliative treatment of malignant esophageal stenosis: the role of selfexpanding stent endoscopic implantation. Dis Esophagus 2000; 13: 301-304. [CrossRef]

19. Kim TO, Kang DH, Kim GH, Heo J, Song GA, Cho M, et al. Self-expandable metallic stents for palliation of patients with malignant gastric outlet obstruction caused by stomach cancer. World J Gastroenterol 2007; 13: 916-920. [CrossRef]

20. Kujawski K, Stasiak M, Rysz J. The evaluation of esophageal stenting complications in palliative treatment of dysphagia related to esophageal cancer. Med Sci Monit 2012; 18: CR323-CR329. [CrossRef] 